\title{
Época de coleta e ácido indolbutírico no enraizamento de miniestacas de pitangueira
}

\section{Period of collection and indolebutyric acid in the rooting of minicuttings of Surinam cherry}

\author{
Martha Lucía Peña Peña ${ }^{1 *}$; Flávio Zanette ${ }^{2}$; Luiz Antonio Biasi ${ }^{2}$
}

Resumo

\begin{abstract}
A miniestaquia é uma técnica de propagação vegetativa promissora. Este estudo traz uma contribuição para o avanço do conhecimento na propagação da pitangueira (Eugenia uniflora L.) (Myrtaceae), árvore nativa do Brasil, com potencial para restauração ecológica, exploração pelas indústrias alimentícias, cosméticas e medicinais, e pode melhorar as condições de vida das comunidades rurais. O objetivo deste trabalho foi avaliar a viabilidade da técnica de miniestaquia na propagação vegetativa de pitangueira, por meio da produtividade e sobrevivência das minicepas, e do enraizamento das miniestacas tratadas com diferentes concentrações do ácido indolbutírico (AIB) nas sucessivas coletas. As minicepas foram obtidas a partir de mudas produzidas via sementes de pitangueira, que foram cultivadas em tubetes, e tiveram seus ápices podados, visando estimular a formação de brotações. Destas minicepas se promoveram oito coletas sucessivas de brotações (miniestacas). O delineamento experimental foi inteiramente casualizado, em arranjo fatorial $8 \times 4$ (oito épocas de coleta de miniestacas e quatro concentrações de AIB), com quatro repetições e 20 miniestacas como unidade experimental. A sobrevivência das minicepas foi de 99,28\% com produtividade média de 362 miniestacas por $\mathrm{m}^{2}$ por mês, considerando 2,5 miniestacas por minicepa por coleta a cada 51 dias. A maior média de produção de miniestacas ocorreu na época 4 de coleta (verão) e a menor na coleta da época 8 (inverno). Verificou-se enraizamento adventício variando de 57,2 (coleta 6 ) até 97,2\% (coleta 1). As miniestacas provenientes das primeiras cinco coletas realizadas até os 247 dias após instalação do minijardim apresentam índices de enraizamento significativamente superiores às provenientes das últimas três coletas, além de melhor qualidade do sistema radicial. $\mathrm{O}$ enraizamento de miniestacas de origem seminal de pitangueira é favorecido com o uso de AIB em concentrações próximas de $2.500 \mathrm{mg} \mathrm{L}^{-1}$.

Palavras-chave: Auxina, época de coleta, Eugenia uniflora L., miniestaquia, minijardim, propagação vegetativa
\end{abstract}

\begin{abstract}
The minicutting is a promising vegetative propagation technique. This study makes a contribution to the advancement of knowledge in the propagation of Surinam cherry (Eugenia uniflora L.) (Myrtaceae), native tree of Brazil, with potential for ecological restoration, exploitation by food, cosmetic and medical industries, and can improve the life in rural communities. The aim of this study was to evaluate the viability of the minicutting technique in the vegetative propagation of Surinam cherry, through productivity and survival of ministumps, and rooting of minicuttings treated with different concentrations of indolebutyric acid (IBA) in the successive collections. Ministumps were obtained from seedlings
\end{abstract}

1 Bióloga, Discente do Curso de Doutorado do Programa de Pós-Graduação em Agronomia, Produção Vegetal, Dept ${ }^{\circ}$ de Fitotecnia e Fitossanitarismo. Setor de Ciências Agrárias, Universidade Federal do Paraná, UFPR, Curitiba, PR, Brasil. E-mail: marthalupe@ bol.com.br

2 Eng $^{\text {os }}$ Agros $^{\text {, }}$ Profs. Drs. Titulares, Dept ${ }^{\circ}$ de Fitotecnia e Fitossanitarismo, Bolsistas de Produtividade em Pesquisa do CNPq, Setor de Ciências Agrárias, UFPR. Curitiba, PR, Brasil. E-mail: flazan@ufpr.br; biasi@ufpr.br

* Autor para correspondência 
produced by Surinam cherry seeds, which were grown in root plugs, and their tips were trimmed so as to stimulate shoot growth. From these ministumps eight successive collections of shoots (minicuttings) were made. A completely randomized experimental design was used in an $8 \times 4$ factorial arrangement (eight collection times of minicuttings and four concentrations of IBA), with four replications and 20 minicuttings as an experimental unit. The survival rate of the ministumps was $99.28 \%$ with mean yield of 362 minicuttings per $\mathrm{m}^{2}$ per month was obtained, considering 2.5 minicuttings per ministump per collection every 51 days. The greatest mean production of minicuttings occurred in the collection 4 (summer) and the least in the collection 8 (winter). Adventitious rooting was observed ranging from 57.2 (collection 6) to $97.2 \%$ (collection 1). The minicuttings derived from the first five collections made up to 247 days after installation of minigarden exhibit significantly greater rooting indices than those derived from the last three collections, in addition to the better quality of the root system. The rooting of minicuttings from seminal origin of Surinam cherry is enhanced with the use of IBA at concentrations of around 2,500 $\mathrm{mg} \mathrm{L}^{-1}$.

Key words: Auxin, collection time, Eugenia uniflora L., minicutting technique, minigarden, vegetative propagation

\section{Introdução}

No Brasil existe uma grande biodiversidade de espécies frutíferas nativas, entre elas a pitangueira (Eugenia uniflora L.) (Myrtaceae) (LORENZI, 2008). Devido à sua adaptabilidade foi disseminada e é atualmente encontrada nas mais variadas regiões do Brasil e do mundo(SILVA, 2006), e seus frutos são apreciados pela fauna silvestre (RANGEL, 2002). No Brasil, apresenta ampla distribuição geográfica, da Bahia ao Rio Grande do Sul. A pitangueira é uma árvore indicada para a recuperação de ecossistemas degradados (BRANDÃO et al., 2002; LORENZI, 2008; VIEIRA NETO, 2002). Esta árvore proporciona diversos usos em reflorestamentos; como planta ornamental; fonte de frutos que são consumidos ao natural e na forma de sucos; em sua composição química é encontrado óleo essencial nas folhas como nos frutos, além de sais minerais e vitamina C (LORENZI, 2002, 2008).

Apesar das amplas possibilidades de expansão e do potencial econômico (RANGEL, 2002), o cultivo comercial no Brasil restringe-se aos Estados de Pernambuco e Bahia (LIRA JÚNIOR et al., 2007). A maioria dos pomares de pitangueira existentes é formada a partir de mudas resultantes da propagação por sementes. Estas mudas não são adequadas para formação de pomares comerciais, pois apresentam como inconveniente grande variabilidade genética. Sendo assim, recomenda-se a substituição de pés- francos por mudas propagadas vegetativamente (BEZERRA et al., 2004). A propagação vegetativa possibilita a produção de mudas com características da planta matriz, permitindo a formação de populações de plantas homogêneas (LIRA JÚNIOR et al., 2007). A estaquia constitui-se em uma das principais técnicas de propagação vegetativa, pode ser utilizada para fins comerciais, assim como auxiliar no resgate e conservação de recursos genéticos florestais (XAVIER et al., 2013).

Entretanto, a propagação de pitangueira por estaquia, com uso de material proveniente de plantas matrizes adultas, tem sido limitada pela dificuldade de enraizamento, aliada à escassez de informações sobre a propagação vegetativa da espécie. Várias espécies de plantas lenhosas mostraram que a capacidade das estacas de formar raízes adventícias diminuiu com o aumento da idade da planta matriz (HARTMANN et al., 2011), e nestes casos, há necessidade do rejuvenescimento do material vegetal original.

Para contornar as dificuldades de enraizamento, a miniestaquia vem sendo estudada a fim de aprimorar o processo de propagação clonal de algumas frutíferas, como araçazeiro (Psidium guineense e Psidium cattleyanum) e goiabeira (Psidium guajava) (ALTOÉ et al., 2011) e algumas espécies florestais nativas do Brasil e exóticas. A miniestaquia é uma técnica que apresenta potencial de utilização em 
espécies lenhosas, como pitangueira. Para varias espécies de Eucalyptus, os resultados obtidos com a miniestaquia têm apresentado diversas vantagens em relação à estaquia convencional na produção de mudas, como a redução da área necessária para a formação do minijardim, redução de custos de transporte e coleta de brotações, maior eficiência das atividades de manejo, além de maior percentual de enraizamento, melhor qualidade do sistema radicial e maior velocidade de emissão das raízes (XAVIER et al., 2003a, 2003b, 2013).

É importante considerar que as minicepas podem ser de origem seminal (seedlings), e a fase adulta naturalmente faz reversão à fase juvenil (rejuvenescimento) durante a reprodução por semente, para restabelecer alto potencial de enraizamento (HARTMANN et al., 2011). Segundo Hackett (1987) a propagação sexuada natural é o método mais eficiente em promover o rejuvenescimento de partes adultas de uma planta, uma vez que origina a parte mais juvenil da planta (embrião) a partir da parte mais madura (órgão frutífero).

No caso da coleta de brotações de mudas produzidas via sementes, segundo Wendling et al. (2005), torna-se imprescindível coletar as sementes de um maior número de árvores matrizes possível, de forma que esses propágulos sejam representativos da população, para que o trabalho de produção vegetativa de mudas de espécies nativas para fins ambientais seja tecnicamente viável. Quando as mudas de uma espécie plantadas numa área em restauração apresentam base genética estreita, ou seja, pouca variabilidade genética, as mesmas serão certamente mais sensíveis a pragas, doenças e estresses ambientais, tendo menores chances futuras de sobrevivência (ELLSTRAND; ELLAM, 1993). Com relação à base genética das mudas de uma espécie, valores acurados requeridos para a coleta do material de propagação dependem, entre outros fatores, do tamanho efetivo de população adotado, da biologia reprodutiva da espécie e de características das populações disponíveis (CARPANEZZI; CARPANEZZI, 2006).
Para que se possam entender melhor as respostas da espécie submetida a esta técnica de propagação é importante considerar os fatores que influenciam o enraizamento adventício (FACHINELLO et al., 2005). A época do ano pode exercer grande influência no enraizamento das estacas, pelo fato de as condições fisiológicas da planta matriz serem influenciadas pelas variações sazonais. Dessa forma, para cada planta e condição ambiental específica, deve-se determinar qual a melhor época de colheita de estacas, bem como a influência da época na produção e qualidade das brotações destinadas ao processo de estaquia (XAVIER et al., 2013).

Neste contexto, o objetivo deste trabalho foi avaliar a viabilidade da técnica de miniestaquia na propagação vegetativa de pitangueira (Eugenia uniflora L.), por meio da produtividade e sobrevivência das minicepas, e do enraizamento das miniestacas tratadas com diferentes concentrações de ácido indolbutírico (AIB) nas sucessivas coletas.

\section{Material e Métodos}

O trabalho foi conduzido em casa de vegetação, localizada no Departamento de Fitotecnia e Fitossanitarismo, Setor de Ciências Agrárias da Universidade Federal do Paraná, Curitiba, Paraná. O minijardim foi instalado a partir de sementes provenientes de frutos maduros de varias plantas da cultivar Tropicana, primeira cultivar de pitangueira comercial brasileira, lançada em 2000 (BEZERRA et al., 2004). A semeadura foi realizada no dia $30 / 06 / 2010$ em tubetes de $240 \mathrm{~cm}^{3}$, colocados em bandejas plásticas de $62 \times 42 \mathrm{~cm}$ com capacidade para 54 tubetes, contendo mistura de substrato comercial vermiculita expandida de granulometria média, Plantmax HT®, e terra $(1: 1: 1)$, sendo irrigadas manualmente com auxilio de mangueira, em casa de vegetação não climatizada. As mudas de origem seminal (seedlings), a partir de sete meses de idade, receberam adubação mensalmente, com 3 mL no substrato por muda. Foi usada a formulação contendo $4 \mathrm{~g} \mathrm{~L}^{-1}$ de ureia, $10 \mathrm{~g} \mathrm{~L}^{-1}$ de superfosfato 
simples, $4 \mathrm{~g} \mathrm{~L}^{-1}$ de cloreto de potássio e $10 \mathrm{~mL} \mathrm{~L}^{-1}$ de complexo de micronutrientes (Micros Q-Green Top () .

No dia 31/05/2011, quando as mudas (seedlings) tinham 11 meses de idade e altura média de $23 \mathrm{~cm}$ tiveram seus ápices podados à altura média de $5 \mathrm{~cm}$ da base, visando estimular a ocorrência de brotações laterais, e mantendo-se dois ou três pares de folhas, constituindo as 209 minicepas para formação do minijardim. As minicepas foram manejadas durante 426 dias. As coletas dos propágulos foram realizadas no minijardim selecionando as brotações que apresentavam um comprimento de aproximadamente $4 \mathrm{~cm}$. As brotações menores que $4 \mathrm{~cm}$ foram mantidas na minicepa para as coletas subsequentes. As coletas foram efetuadas cada vez que o minijardim tinha quantidade suficiente de brotações para a instalação do experimento de miniestaquia, deste modo foi possível efetuar oito coletas durante o período de 12 meses, nas datas de 10/08, 22/09, 03/11, 20/12 de 2011, e 02/02, $26 / 03,18 / 05,30 / 07$ de 2012. A data de cada coleta permitiu ainda especificar a estação correspondente, ou seja, as coletas 1 e 8 ocorreram no inverno, 2 e 3 na primavera, 4 e 5 no verão e, 6 e 7 no outono. De acordo com a temperatura média mensal registrada pela estação meteorológica de Curitiba, fornecida pelo Sistema Meteorológico do Paraná (SIMEPAR, 2013), calculou-se a média para as estações ao longo do ano, obteve-se $14,15{ }^{\circ} \mathrm{C}$ no inverno 2011 , $17,35{ }^{\circ} \mathrm{C}$ na primavera, $20,55{ }^{\circ} \mathrm{C}$ no verão, 16,92 ${ }^{\circ} \mathrm{C}$ no outono e $15,2{ }^{\circ} \mathrm{C}$ no inverno 2012 . As coletas foram efetuadas em diferentes intervalos de tempo, o intervalo entre cada coleta variou de 42 a 73 dias, mantendo-se a padronização estabelecida quanto à seleção de brotações. Em cada coleta, todas as brotações com comprimento maior ou igual a 4 $\mathrm{cm}$ foram selecionadas e coletadas pela manhã e imediatamente acondicionadas em bandejas com água para posterior preparo das miniestacas. Em cada coleta foi realizada a contagem de brotações coletadas por minicepa para a obtenção da produção média do minijardim (brotações por minicepa e brotações por $\mathrm{m}^{2}$ ). Após cada coleta de brotações, as minicepas receberam no substrato $3 \mathrm{~mL}$ da mesma solução aquosa de adubo utilizada para as mudas.

As miniestacas apicais foram preparadas utilizando-se as brotações, sem desprezar a porção apical e mantendo-se o comprimento aproximado de $4 \mathrm{~cm}$ e diâmetro de $0,05 \mathrm{~cm}$, mantendo-se um par de folhas apicais inteiras, e um par de folhas basais com a área de seu limbo reduzida à metade para a redução da perda de água pela transpiração foliar. Para manter as condições de turgescência do material vegetal, as miniestacas foram acondicionadas em bandejas com água, e em seguida foram tratadas com o regulador vegetal. A base das miniestacas foi submetida a quatro concentrações de soluções hidroalcoólicas $(50 \% \mathrm{v} / \mathrm{v})$ de ácido indolbutírico (AIB) $\left(0 ; 1.000 ; 2.000\right.$ e $\left.4.000 \mathrm{mg} \mathrm{L}^{-1}\right)$, por imersão rápida por $5 \mathrm{~s}$. Não foi realizado nenhum tratamento de desinfestação previamente a introdução das miniestacas no substrato. O plantio foi realizado em tubetes de $53 \mathrm{~cm}^{3}$, contendo substrato comercial vermiculita expandida de granulometria média, em casa de vegetação não climatizada com irrigação intermitente, por microaspersão. $\mathrm{O}$ intervalo de irrigação das $08 \mathrm{~h} 00$ às $17 \mathrm{~h} 00$ era de $15 \mathrm{~s}$ a cada 30 min; das $17 \mathrm{~h} 00$ às $23 \mathrm{~h} 00$ de $15 \mathrm{~s}$ a cada $60 \mathrm{~min}$; das $23 \mathrm{~h} 00$ às $8 \mathrm{~h} 00$ de $15 \mathrm{~s}$ a cada três horas. O período de permanência no leito de enraizamento foi de 120 dias.

O delineamento experimental utilizado foi inteiramente casualizado, em arranjo fatorial (8x4), sendo os fatores constituídos por oito coletas sucessivas de brotações e quatro concentrações de AIB, com quatro repetições, e as unidades experimentais foram formadas por 20 miniestacas. Foramanalisadasasseguintesvariáveis: porcentagem de miniestacas enraizadas (miniestacas com indução de primórdios radiciais, com no mínimo $1 \mathrm{~mm}$ de comprimento, podendo ou não apresentar calos); número médio de raízes formadas por miniestaca; comprimento $(\mathrm{cm})$ médio das três maiores raízes formadas por miniestaca; massa de matéria seca de raízes $(\mathrm{mg})$ por miniestaca; porcentagem de 
miniestacas sobreviventes (miniestacas que não formaram raízes, mas que permaneceram vivas, podendo ou não apresentar calos); e porcentagem de miniestacas mortas (miniestacas com necrose em toda ou na maior parte de sua extensão).

Para cada variável, inicialmente as variâncias dos tratamentos foram avaliadas quanto a sua homogeneidade pelo teste de Bartlett. Para as variáveis cujas variâncias mostraram-se homogêneas, os dados foram submetidos à análise de variância, e para comparação entre épocas de coleta as médias dos tratamentos foram comparadas pelo teste de Tukey a $5 \%$ de probabilidade. As variáveis que apresentaram variâncias heterogêneas tiveram os valores originais transformados para posterior análise pelo mesmo teste. Os dados de porcentagem de miniestacas enraizadas foram transformados segundo a equação $\operatorname{arcsen} \sqrt{ } \mathrm{x} / 100$; os dados referentes a comprimento médio das três maiores raízes por miniestaca foram transformados segundo a equação $\sqrt{x}$; e os dados obtidos para a massa de matéria seca das raízes por miniestaca foram transformados segundo a equação $\log$ $(\mathrm{x}), \mathrm{c}=1$. Os dados obtidos para o número médio de raízes por miniestaca foram analisados, sem necessidade de transformação. Para a comparação entre concentrações de AIB foi aplicada análise de regressão. O programa estatístico utilizado foi o Assistat, versão 7.6 beta.

\section{Resultados e Discussão}

\section{Minicepas}

As minicepas de origem seminal, cultivadas em tubetes de $240 \mathrm{~cm}^{3}$, no minijardim de pitangueira apresentaram alta sobrevivência $(99,28 \%)$ após oito coletas sucessivas de brotações durante o período do experimento. Não houve incidência de doenças que comprometessem a sobrevivência das minicepas. Entre os estudos com espécies florestais nativas brasileiras, Cunha et al. (2008), para corticeira-do-mato (Erythrina falcata Benth.), e Xavier et al. (2003a), para cedro rosa (Cedrela fissilis Vell.) após quatro coletas, não observaram mortalidade das minicepas produzidas via semente, em sistema de minijardim em tubete contendo 110 e $200 \mathrm{~cm}^{3}$ de substrato respectivamente. Resultados diferentes foram encontrados por Ferriani et al. (2011), trabalhando com Piptocarpha angustifolia Dusén ex. Malme relataram redução do número de minicepas, atribuída ao período de aclimatação do material durante a implantação do minijardim em sistema semi-hidropônico.

Os resultados da produção de brotações (miniestacas) provenientes de minicepas de pitangueira estão apresentados na Tabela 1 . Observou-se que as minicepas possuem capacidade de emissão de novas brotações após cada coleta de miniestacas. A poda realizada em plantas juvenis induziu o desenvolvimento de brotações juvenis, que vem a ser uma das alternativas para a obtenção de propágulos com maior potencial rizogênico. A poda é um aspecto importante do manejo de plantas matrizes em relação à manutenção da juvenilidade da planta matriz (HARTMANN et al., 2011). Castro et al. (2010) trabalhando no sistema de produção de material propagativo de pessegueiro (Prunus pérsica L. Batsch), relataram que a poda favorece o desenvolvimento de gemas laterais, estimulando bifurcações que poderão ampliar a área de coleta de material propagativo. 
Tabela 1. Produtividade média de brotações de Eugenia uniflora L. em oito coletas sucessivas realizadas no minijardim durante o período do experimento (agosto de 2011 a julho de 2012).

\begin{tabular}{|c|c|c|c|c|c|c|c|c|}
\hline \multirow[t]{3}{*}{ Coleta } & \multirow{3}{*}{$\begin{array}{l}\text { Data } \\
\text { de } \\
\text { coleta }\end{array}$} & \multirow{3}{*}{$\begin{array}{c}\text { Intervalo } \\
\text { entre as } \\
\text { coletas } \\
\text { (dias) }\end{array}$} & \multirow{3}{*}{$\begin{array}{c}\text { Dias após } \\
\text { instalação do } \\
\text { minijardim } \\
\text { (poda seedlings) }\end{array}$} & \multirow{3}{*}{$\begin{array}{c}\mathrm{N}^{\circ} \\
\text { minicepas } \\
\text { sobreviventes }\end{array}$} & \multirow{3}{*}{$\begin{array}{c}\text { Brotações/ } \\
\text { coleta } \\
\text { (miniestacas) }\end{array}$} & \multicolumn{3}{|c|}{ Produtividade média } \\
\hline & & & & & & \multicolumn{3}{|c|}{ brotações / } \\
\hline & & & & & & $\begin{array}{l}\text { minicepa } \\
\text { / coleta }\end{array}$ & $\begin{array}{c}\mathrm{m}^{2} \\
/ \text { coleta }\end{array}$ & $\begin{array}{l}\mathrm{m}^{2} \\
/ \text { mês }\end{array}$ \\
\hline 1 & $10 / 08 / 2011$ & - & 71 & 209 & 469 & 2,2 & 560,9 & 237 \\
\hline Média & (Inverno) & - & - & 209 & - & 2,2 & 560,9 & - \\
\hline Total & - & - & - & - & 469 & 2,2 & 560,9 & - \\
\hline 2 & $22 / 09 / 2011$ & 43 & 114 & 209 & 453 & 2,2 & 541,8 & 378 \\
\hline 3 & $03 / 11 / 2011$ & 42 & 156 & 209 & 566 & 2,7 & 677,0 & 483 \\
\hline Média & (Primavera) & 43 & - & 209 & - & 2,4 & 609,4 & - \\
\hline Total & - & - & - & - & 1019 & 4,9 & 1218,8 & - \\
\hline 4 & $20 / 12 / 2011$ & 47 & 203 & 209 & 720 & 3,4 & 861,1 & 550 \\
\hline 5 & $02 / 02 / 2012$ & 44 & 247 & 209 & 532 & 2,5 & 636,3 & 434 \\
\hline Média & (Verão) & 46 & - & 209 & - & 3,0 & 748,7 & - \\
\hline Total & - & - & - & - & 1252 & 6,0 & 1497,4 & - \\
\hline 6 & $26 / 03 / 2012$ & 53 & 300 & 206 & 586 & 2,8 & 700,9 & 397 \\
\hline 7 & $18 / 05 / 2012$ & 53 & 353 & 206 & 464 & 2,3 & 555,0 & 314 \\
\hline Média & (Outono) & 53 & - & 206 & - & 2,5 & 627,9 & - \\
\hline Total & - & - & - & - & 1050 & 5,1 & 1255,8 & - \\
\hline 8 & $30 / 07 / 2012$ & 73 & 426 & 206 & 331 & 1,6 & 395,9 & 163 \\
\hline Média & (Inverno) & - & - & 206 & - & 1,6 & 395,9 & - \\
\hline Total & - & - & - & - & 331 & 1,6 & 395,9 & - \\
\hline Média G & eral & 51 & - & - & 515 & 2,5 & 616,1 & 362 \\
\hline
\end{tabular}

Em termos gerais, observou-se o aumento da produtividade das minicepas de pitangueira da segunda até a quarta coleta realizada aos 203 dias após instalação do minijardim (poda de seedlings) (Tabela 1). Estes resultados corroboram aos constatados por Altoé et al. (2011), em minicepas de origem seminal de três espécies frutíferas da família Myrtaceae, gênero Psidium, goiabeira (P.guajava L.) da cultivar Paluma, e araçazeiro de plantas nativas de restinga (P.cattleyanum Sabine e P.guineense Swartz), nas quais verificaram que até os 166 dias (coleta da época 4) após o desponte foi observado aumento do número de brotações emitidas pelas minicepas. Esses autores relataram que este comportamento poderia estar relacionado a uma adaptação das minicepas à perda da dominância apical na medida em que se realizavam as sucessivas coletas das brotações nas minicepas.

Os resultados também confirmam aos verificados por Dias et al. (2012), trabalhando com angico- vermelho (Anadenanthera macrocarpa (Benth) Brenan), espécie florestal nativa brasileira, na qual observaram aumento gradativo da produção de miniestacas da primeira até a terceira coleta. Afirmaram que o número de miniestacas obtidas varia em função da espécie/clone, sistema e manejo do minijardim, condições ambientais, e vigor fisiológico das minicepas.

De acordo com as avaliações, a maior produtividade das minicepas ocorreu na quarta coleta (Tabela 1). Esta coleta de brotações foi realizada no período de temperatura mais elevada (média da temperatura ambiente em torno de 20,55 $\left.{ }^{\circ} \mathrm{C}\right)$ em relação às demais coletas. A temperatura possivelmente contribuiu para o desenvolvimento de gemas, e crescimento de brotações. Esses resultados confirmam os encontrados em Sapium glandulatum (Vell.) Pax., por Ferreira et al. (2010), que observaram, no verão, a maior produção de miniestacas (2,2 miniestacas por minicepa em tubete 
contendo $205 \mathrm{~cm}^{3}$ de substrato e 609 miniestacas por $\mathrm{m}^{2}$ ), onde as temperaturas mais elevadas favoreceram o desenvolvimento das brotações.

Observou-se posterior queda nas coletas 5 a 8 (Tabela 1). Na coleta 8 foi detectada diminuição mais acentuada na emissão de brotações de pitangueira. As minicepas apresentaram tendência de exaustão com o decorrer destas coletas. Este comportamento, observado em relação às diferentes coletas, está de acordo com resultados obtidos para erva-mate (Ilex paraguariensis) por Wendling et al. (2007), os autores observaram o aumento da produtividade de minicepas da primeira até a quarta coleta, com posterior queda nas coletas 5, 6 e 7. Em outro estudo, Brondani et al. (2012), ao trabalharem com Eucalyptus benthamii $\times$ Eucalyptus dunnii, relataram que a queda ou aumento da produção de miniestacas ocorridos dentro do período experimental estariam ligados, possivelmente, a fatores ambientais como a variação da temperatura e luminosidade, condicionadas pela sazonalidade, e ao manejo adotado para as minicepas. A partir da adequação de manejo da espécie em estudo, principalmente em termos de nutrição, será possível aumentar o numero de brotações por minicepa (FERRIANI et al., 2011).

A produção de miniestacas/minicepa/coleta variou de 1,6 (na coleta da época 8) a 3,4 (na coleta da época 4). Obteve-se uma produtividade média de 2,5 miniestacas por minicepa em cada coleta a cada 51 dias (Tabela 1), em torno de 1,47 miniestaca por minicepa a cada 30 dias. Este resultado encontrase próximo ao relatado para cedro-rosa (Cedrela fissilis) por Xavier et al. (2003a), e para corticeirado-mato (Erythrina falcata Benth) por Cunha et al. (2008) que foi de 1,3 miniestaca por minicepa a cada 30 dias, em minijardim cultivado em tubetes de $200 \mathrm{~cm}^{3}$. A produtividade média de brotações de pitangueira por $\mathrm{m}^{2}$ de minijardim a cada mês (362) variou entre 163 e 550 (Tabela 1), e foi superior ao observado no sistema semi-hidropônico para Piptocarpha angustifolia Dusen ex. Malme (variando entre 113,4 e 259,2 brotações $/ \mathrm{m}^{2} / \mathrm{mês}$ ) (FERRIANI et al., 2011). Assim, estes resultados indicaram a viabilidade do sistema adotado para produção de propágulos vegetativos de pitangueira em função da produtividade média obtida.

\section{Miniestaquia}

Verificou-se na análise de variância que não houve interação estatisticamente significativa entre os fatores (época de coleta e concentração de ácido indolbutírico) para a variável porcentagem de miniestacas enraizadas, comprimento médio de raízes, número e massa seca de raízes formadas por miniestaca. O fator época de coleta apresentou efeito significativo de forma independente para a variável porcentagem de enraizamento, as miniestacas provenientes das primeiras cinco coletas apresentaram índices significativamente superiores aos obtidos nas miniestacas provenientes das ultimas três coletas (Tabela 2).

O enraizamento da pitangueira foi observado na miniestaquia proveniente de brotações de minicepas de origem seminal (Tabela 2). De modo geral, os índices de enraizamento observados podem ser atribuídos a vários fatores, dentre eles, à idade da planta matriz, o que demonstra o efeito positivo da juvenilidade no desenvolvimento do sistema radicial adventício. Altoé et al. (2011), afirmaram que o elevado percentual de enraizamento em miniestacas do gênero Psidium pode estar associado ao material propagativo utilizado, que foi de origem juvenil. Altoé e Marinho (2012), trabalhando com miniestacas de goiabeira 'Paluma', relataram que para uma mesma cultivar, o percentual de enraizamento pode variar com a idade do material propagativo e com fatores ambientais. Uma das mais consistentes expressões da maturação em plantas lenhosas tem sido a transição da alta para a baixa capacidade de enraizamento das estacas (HACKETT, 1987). 
Tabela 2. Porcentagem de miniestacas de Eugenia uniflora L. enraizadas, número de raízes formadas por miniestaca, comprimento médio das três maiores raízes e massa de matéria seca de raízes por miniestaca, ao longo de oito coletas sucessivas de miniestacas, tratadas com diferentes concentrações de ácido indolbutírico (AIB) ${ }^{(1)}$.

\begin{tabular}{|c|c|c|c|c|c|c|c|c|c|c|}
\hline \multirow[b]{2}{*}{$\begin{array}{c}{[\mathrm{AIB}]} \\
\left(\mathrm{mg} \mathrm{L}^{-1}\right)\end{array}$} & \multicolumn{9}{|c|}{ Coletas } & \multirow[b]{2}{*}{ Médias } \\
\hline & $\begin{array}{c}1 \\
\text { inverno }\end{array}$ & & $\begin{array}{c}2 \\
\text { primavera }\end{array}$ & $\begin{array}{c}3 \\
\text { primavera }\end{array}$ & $\begin{array}{c}4 \\
\text { verão }\end{array}$ & $\begin{array}{c}5 \\
\text { verão }\end{array}$ & $\begin{array}{c}6 \\
\text { outono }\end{array}$ & $\begin{array}{c}7 \\
\text { outono }\end{array}$ & $\begin{array}{c}8 \\
\text { inverno }\end{array}$ & \\
\hline \multicolumn{11}{|c|}{ Porcentagem de miniestacas enraizadas } \\
\hline 0 & 94,6 & & 86,5 & 93,7 & 90,0 & 87,5 & 53,8 & 57,5 & 62,5 & 78,3 \\
\hline 1000 & 100,0 & & 85,6 & 88,7 & 88,8 & 95,0 & 62,5 & 76,3 & 70,0 & 83,3 \\
\hline 2000 & 97,2 & & 88,7 & 92,5 & 96,2 & 92,5 & 57,5 & 70,0 & 82,5 & 84,6 \\
\hline 4000 & 97,2 & & 84,6 & 96,2 & 90,0 & 81,3 & 55,0 & 80,0 & 60,0 & 80,5 \\
\hline Médias & 97,2 & $\mathrm{a}$ & $86,4 \mathrm{~b}$ & $92,8 \mathrm{ab}$ & $91,2 \mathrm{ab}$ & $89,1 \mathrm{~b}$ & $57,2 \mathrm{c}$ & $70,9 \mathrm{c}$ & $68,8 \mathrm{c}$ & \\
\hline C.V. $(\%)$ & 13,56 & & & & & & & & & \\
\hline \multicolumn{11}{|c|}{ Número de raízes/miniestaca } \\
\hline 0 & 1,4 & & 1,2 & 1,2 & 1,2 & 1,3 & 1,2 & 1,0 & 1,2 & 1,2 \\
\hline 1000 & 1,4 & & 1,4 & 1,3 & 1,4 & 1,4 & 1,2 & 1,3 & 1,3 & 1,3 \\
\hline 2000 & 1,6 & & 1,6 & 1,4 & 1,5 & 1,3 & 1,1 & 1,4 & 1,5 & 1,4 \\
\hline 4000 & 1,7 & & 1,5 & 1,4 & 1,6 & 1,5 & 1,2 & 1,4 & 1,3 & 1,5 \\
\hline Médias & 1,5 & $\mathrm{a}$ & $1,4 \mathrm{ab}$ & $1,4 \mathrm{~b}$ & $1,4 \mathrm{ab}$ & $1,4 \mathrm{ab}$ & $1,2 \mathrm{c}$ & 1,3 bc & $1,3 \mathrm{bc}$ & \\
\hline C.V. $(\%)$ & 12,08 & & & & & & & & & \\
\hline \multicolumn{11}{|c|}{ Comprimento médio de raízes $(\mathrm{cm})$} \\
\hline 0 & 5,6 & & 4,1 & 4,2 & 1,5 & 1,8 & 0,4 & 1,2 & 1,4 & 2,5 \\
\hline 1000 & 6,2 & & 4,9 & 5,2 & 2,4 & 1,8 & 0,4 & 1,2 & 1,6 & 3,0 \\
\hline 2000 & 5,9 & & 5,2 & 4,7 & 2,5 & 2,0 & 0,4 & 1,7 & 2,3 & 3,1 \\
\hline 4000 & 5,9 & & 4,7 & 4,5 & 1,4 & 2,0 & 0,4 & 2,1 & 2,6 & 2,9 \\
\hline Médias & 5,9 & $\mathrm{a}$ & $4,7 \mathrm{ab}$ & $4,6 \mathrm{~b}$ & $1,9 \mathrm{c}$ & $1,9 \mathrm{c}$ & $0,4 \mathrm{~d}$ & $1,6 \mathrm{c}$ & $2,0 \mathrm{c}$ & \\
\hline C.V. $(\%)$ & 15,8 & & & & & & & & & \\
\hline \multicolumn{11}{|c|}{ Massa seca de raízes/miniestaca $(\mathrm{mg})$} \\
\hline 0 & 17,8 & & 10,1 & 14,9 & 5,2 & 5,6 & 1,1 & 2,6 & 4,2 & 7,7 \\
\hline 1000 & 23,3 & & 12,4 & 21,7 & 10,7 & 7,6 & 0,9 & 3,9 & 4,8 & 10,7 \\
\hline 2000 & 22,6 & & 15,1 & 22,7 & 11,6 & 7,9 & 1,1 & 5,8 & 8,3 & 11,9 \\
\hline 4000 & 26,3 & & 15,0 & 19,8 & 6,0 & 9,6 & 1,0 & 7,3 & 9,1 & 11,8 \\
\hline Médias & 22,5 & $\mathrm{a}$ & $13,1 \quad b$ & 19,8 a & $8,4 \mathrm{c}$ & $7,7 \quad \mathrm{c}$ & $1,0 \mathrm{e}$ & $4,9 \mathrm{~d}$ & $6,6 \mathrm{~cd}$ & \\
\hline C. V. $(\%)$ & 16,26 & & & & & & & & & \\
\hline
\end{tabular}

${ }^{(1)}$ Médias seguidas pela mesma letra minúscula na linha não diferem, entre si, pelo teste de Tukey, a 5\% de probabilidade.

Os resultados de enraizamento adventício especialmente das miniestacas provenientes das primeiras cinco coletas de pitangueira (Tabela 2) aproximaram-se àqueles obtidos com miniestacas provenientes de minicepas de origem seminal (seedlings) de outras espécies frutíferas, como goiabeira, para a qual Marinho et al. (2009) verificaram que $100 \%$ das miniestacas enraizaram, e maracujazeiro amarelo (Passiflora edulis $f$, Flavicarpa) tendo Carvalho et al. (2007) obtido enraizamento próximo a $100 \%$, e de outras espécies, como Pinus taeda L., para a qual Alcântara et al. (2007) relataram que $85 \%$ das miniestacas provenientes da primeira coleta enraizaram.

Para pitangueira, a maior capacidade para formar raízes nas primeiras coletas pode estar relacionada com a condição fisiológica e balanço hormonal endógeno favorável da planta matriz nesse período do ano, promovendo a indução radicial. Xavier et al. (2013) relataram que entre os principais fatores que afetam a propagação pelo enraizamento de estacas estão aqueles relacionados com o genótipo, 
as condições fisiológicas e de nutrição mineral da planta fornecedora de estacas e os fatores relacionados com a manipulação das condições ambientais, entre outros.

Os altos índices de enraizamento observados nas miniestacas provenientes das primeiras cinco coletas (Tabela 2), (coleta 1 no inverno-2011; coleta 2 e 3 na primavera-2012; coleta 4 e 5 no verão-2012) indicam que o enraizamento ocorre em miniestacas coletadas durante a maior parte do ano (média de temperatura ambiente variando entre 14,15 e $20,55{ }^{\circ} \mathrm{C}$ ), revelando possivelmente a adaptabilidade da espécie a diversas condições climáticas. Para muitas espécies, é crítico que as estacas sejam coletadas durante um período ótimo para que ocorra o enraizamento. No que se refere à época mais adequada para a coleta das estacas, está relacionada com a condição fisiológica da planta matriz (HARTMANN et al., 2011).

É importante lembrar que houve tendência à diminuição da produção de brotações das minicepas nas últimas coletas (Tabela 1), além disso, foram observados menores índices de enraizamento nas miniestacas nas últimas coletas (coleta 6,7 e 8 ) (Tabela 2), e isso aconteceu possivelmente devido ao fato de que as coletas sucessivas de brotações causaram esgotamento das reservas, e debilitaram as minicepas, portanto, as brotações emitidas provavelmente apresentavam condições fisiológicas menos favoráveis ao enraizamento das miniestacas.

Para prevenir o esgotamento das minicepas de pitangueira, e a diminuição do índice de enraizamento das miniestacas, recomenda-se que, nestes casos, o intervalo entre coletas seja aumentado, as minicepas sejam passadas a recipiente de maior tamanho e os requerimentos nutricionais sejam ajustados. Souza et al. (2009), para cedro australiano (Toona ciliata M. Roemer) relataram que, o maior intervalo entre as coletas permitiu maior acúmulo de reservas nas miniestacas utilizadas. Cunha et al. (2005), recomendaram que de acordo com a espécie, a adoção de intervalos longos entre coletas de miniestacas poderia ser conveniente, pois desta forma, as minicepas sofreriam menor estresse proveniente de podas consecutivas, aumentando a produtividade. $\mathrm{O}$ estado nutricional da planta matriz é de grande importância não apenas quanto ao aspecto do seu vigor vegetativo e da produção de brotações (TITON et al., 2003), mas também quanto a concentração dos elementos minerais nos propágulos vegetativos, efeito altamente significativo nos índices de enraizamento e na velocidade de formação de raízes (ALFENAS et al., 2009; XAVIER et al., 2013).

As miniestacas de pitangueira provenientes das primeiras cinco coletas, em geral, apresentaram sistema radicial de melhor qualidade, o que pode ser evidenciado pela variável número de raízes, comprimento médio de raízes, e massa seca de raízes por miniestaca (Tabela 2). Na coleta da época 6 observou-se queda na qualidade do sistema radicial, o que pode ser corroborado pelas características avaliadas. As mudas posteriormente produzidas a partir de miniestacas das primeiras cinco coletas, por apresentarem sistema radicial de melhor qualidade, provavelmente possuirão um desempenho mais satisfatório no campo. O desenvolvimento do sistema radicial é um fator essencial para o bom desenvolvimento da muda após o transplantio para o campo (LIMA et al., 2009).

Com relação à influência da aplicação de AIB, as curvas de tendência ajustadas e respectivas equações para representar a relação entre cada variável e as concentrações de AIB testadas, são apresentadas na Figura 1. Na análise de regressão pode se constatar que houve um aumento do número de raízes formadas por miniestaca, com a elevação da concentração de AIB. Verificou-se que houve um leve aumento da porcentagem de enraizamento, comprimento de raízes e massa seca de raízes por miniestaca, com a elevação da concentração de AIB, e inicio da diminuição dos índices para estas variáveis em concentrações superiores de $2.500 \mathrm{mg}$ $\mathrm{L}^{-1}$. 
Figura 1. Porcentagem de miniestacas de Eugenia uniflora L. enraizadas (a), número de raízes formadas por miniestaca (b), comprimento médio das três maiores raízes (c) e massa de matéria seca de raízes por miniestaca (d), ao longo de oito coletas sucessivas de miniestacas, tratadas com diferentes concentrações de ácido indolbutírico.
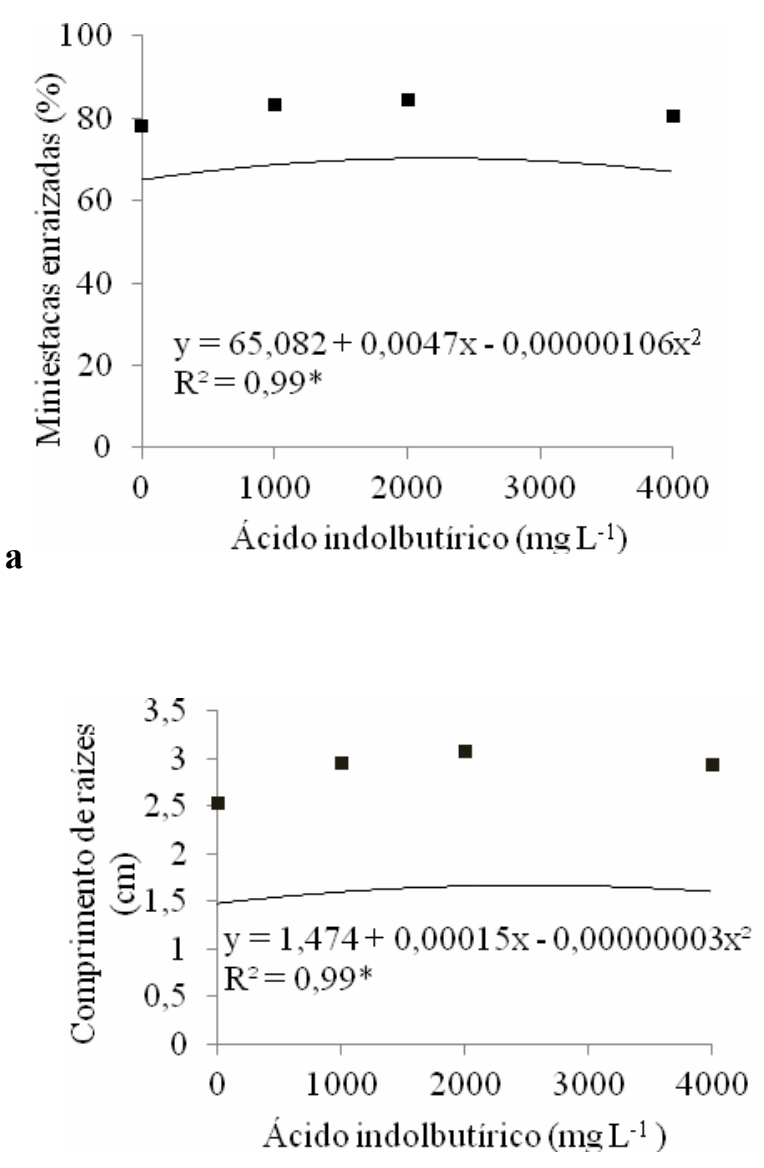

C

Por cálculo da melhor concentração de AIB a ser utilizada, seria mais favorável o uso de 2.350 $\mathrm{mg} \mathrm{L}^{-1}$ para enraizamento das miniestacas, 3.750 $\mathrm{mg} \mathrm{\textrm {L } ^ { - 1 }}$ para número de raízes por miniestaca, $2.500 \mathrm{mg} \mathrm{L}^{-1}$ para comprimento médio de raízes, e $2.453 \mathrm{mg} \mathrm{L}^{-1}$ de AIB para massa seca de raízes. O enraizamento adventício de miniestacas chegou a 84,6 \% com a utilização de $2.000 \mathrm{mg} \mathrm{L}^{-1}$ de AIB. Lattuada et al. (2011), trabalhando com estacas herbáceas de pitangueira observaram 36,09\% (sem AIB) e 44,15\% (com $2.000 \mathrm{mg} \mathrm{L}^{-1}$ de AIB) de enraizamento. Oliveira et al. (2012), alcançaram 68\% de miniestacas apicais enraizadas de Melaleuca alternifólia Cheel (Myrtaceae) e melhor qualidade do sistema radicial com aplicação de $500 \mathrm{mg} \mathrm{L}^{-1}$
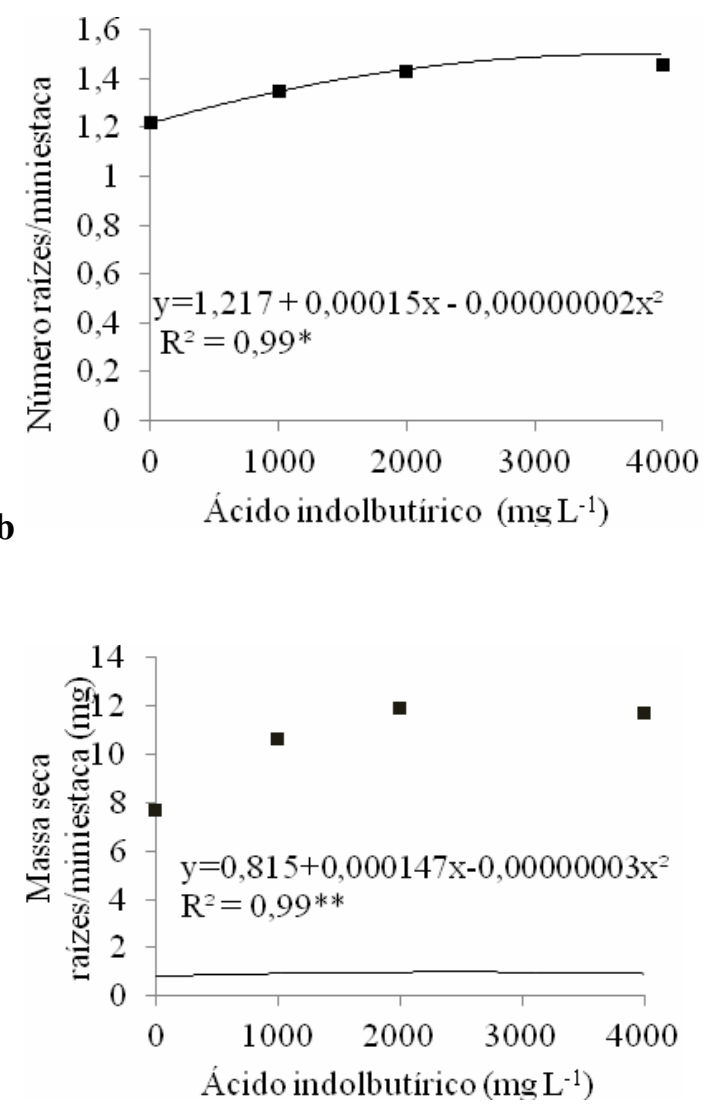

D

de AIB. O efeito positivo da aplicação de AIB no enraizamento de estacas também foi observado por Marangon e Biasi (2013), para mirtilo (Vaccinium ashei), e a concentração de $2.000 \mathrm{mg} \mathrm{L}^{-1}$ foi a mais favorável nas cultivares Bluegem e Powderblue.

Diferentemente do verificado no presente trabalho, Dias et al. (2012), trabalhando com miniestacas de Angico-vermelho (Anadenanthera macrocarpa (Benth) (Brenan), e Ferreira et al. (2010), com miniestacas de Sapium glandulatum (Vell.) Pax notaram que essas espécies apresentam aptidão natural ao enraizamento das miniestacas, não justificando a aplicação de ácido indolbutírico para a indução de raízes adventícias. 
Em outros estudos, Cunha et al. (2008), observaram boa porcentagem de enraizamento de miniestacas de corticeira-do-mato (Erythrina falcata Benth) com média geral de $85,5 \%$, sem a aplicação de AIB, Silva et al. (2010), indicaram que a aplicação de AIB é desnecessária para enraizamento de miniestacas de guanandi (Calophyllum brasiliensis), e Sousa et al. (2013), observaram $88,3 \%$ de estacas herbáceas de figueira (Ficus carica L.) enraizadas, sem a aplicação de AIB. Embora, para estacas herbáceas geralmente não seja necessário o uso de auxinas, este regulador é frequentemente usado para aumentar a porcentagem de estacas que formam raízes, acelerar a iniciação da formação de raízes, aumentar a uniformidade do enraizamento, e desenvolver o sistema radicial de melhor qualidade (HACKETT, 1987; HARTMANN et al., 2011).

Em virtude da existência de uma ou mais variâncias igual a zero, o programa de análise estatística indicou que não era possível aplicar o teste para as seguintes variáveis: porcentagem de miniestacas sobreviventes e mortas. Em geral, verificou-se baixa taxa de mortalidade (variando entre 0,0 a 7,6), à exceção da última miniestaquia instalada (coleta 8) com a maior mortalidade das miniestacas $(15,9 \%)$, o que indica que este material proveniente das minicepas após sete coletas é menos favorável para a miniestaquia de pitangueira.

Conclui-se, que as minicepas de origem seminal de pitangueira constituem uma opção promissora para produção de propágulos vegetativos juvenis, e a quarta coleta no verão é a época de coleta de maior produtividade. As miniestacas das primeiras cinco coletas realizadas até os 247 dias após implantação do minijardim proporcionam maior porcentagem de enraizamento e melhor qualidade do sistema radicial. O enraizamento de miniestacas é favorecido com o uso de ácido indolbutírico em concentrações próximas de $2.500 \mathrm{mg} \mathrm{L}^{-1}$.

\section{Agradecimentos}

À CAPES, pela concessão de bolsa de estudo. Ao Dr. Roberto Jose Mello de Moura da Estação Experimental de Itambé - PE, do Instituto Agronômico de Pernambuco (IPA), pelo envio das sementes da pitangueira.

\section{Referências}

ALCÂNTARA, G. B. de; RIBAS, L. L. F.; HIGA, A. R.; ZUFFELLATO-RIBAS, K. C.; KOEHLER, H. S. Efeito da idade da muda e da estação do ano no enraizamento de miniestacas de Pinus taeda L. Revista Árvore, Viçosa, MG, v. 31, n. 3, p. 399-404, 2007.

ALFENAS, A. C.; ZAUZA, E. A. V.; MAFIA, R. G.; ASSIS, T. F. Clonagem e doenças do eucalipto. 2. ed. Viçosa, MG: Ed. UFV, 2009. 500 p.

ALTOÉ, J. A.; MARINHO, C. S. Miniestaquia seriada na propagação da goiabeira 'Paluma'. Revista Brasileira de Fruticultura, Jaboticabal, v. 34, n. 2, p. 576-580, 2012.

ALTOÉ, J. A.; MARINHO, C. S.; TERRA, M. I. da C.; BARROSO, D. G. Propagação de araçazeiro e goiabeira via miniestaquia de material juvenil. Bragantia, Campinas, v. 70, n. 2, p. 312-318, 2011.

BEZERRA, J. E. F.; LEDERMAN, I. E.; SILVA JUNIOR, J. F. da; ALVES, M. A. Comportamento da pitangueira (Eugenia uniflora L.) sob irrigação na região do vale do rio moxotó, Pernambuco. Revista Brasileira de Fruticultura, Jaboticabal, v. 26, n. 1, p. 177-179, 2004.

BRANDÃO, M.; LACA-BUENDÍA, J. P.; MACEDO, J. F. Árvores nativas e exóticas do estado de Minas Gerais. Belo Horizonte: EPAMIG, 2002. 528 p.

BRONDANI, G. E.; WENDLING, I.; GROSSI, F.; DUTRA, L. F.; ARAUJO, M. A. de. Miniestaquia de Eucalyptus benthamii x Eucalyptus dunnii: (I) Sobrevivência de minicepas e produção de miniestacas em função das coletas e estações do ano. Ciência Florestal, Santa Maria, v. 22, n. 1, p. 11-21, 2012.

CARPANEZZI, A. A.; CARPANEZZI, O. T. B. Espécies nativas recomendadas para recuperação ambiental no Estado do Paraná, em solos não degradados. Colombo: EMBRAPA Florestas, 2006. 52 p. (Documentos, 136).

CARVALHO, R. I. N.; SILVA, I. D.; FAQUIM, R. Enraizamento de miniestacas de maracujazeiro amarelo. Semina: Ciências Agrárias, Londrina, v. 28, n. 3, p. $387-$ 392, 2007. 
CASTRO, L. A. S. de; MELO, M.; MATTOS, M. L. T. Tratos culturais para manutenção das plantas nas borbulheiras. In: CASTRO, L. A. S. de (Ed.). Sistema de produção de material propagativo de pessegueiro com alta sanidade. Pelotas: Embrapa Clima Temperado, 2010. p. 69-72. (Sistema de Produção, 18).

CUNHA, A. C. M. C. M.; WENDLING, I.; SOUZA JÚNIOR, L. Miniestaquia em sistema de hidroponia e em tubetes de corticeira-do-mato. Ciência Florestal, Santa Maria, v.18, n.1, p. 85-92, 2008.

Produtividade e sobrevivência de minicepas de Eucalyptus benthamii Maiden et Cambage em sistema de hidroponia e em tubete. Ciência Florestal, Santa Maria, v. 15, n. 3, p. 307-310, 2005.

DIAS, P. C.; XAVIER, A.; OLIVEIRA, L. S. de; PAIVA, H. N. de; CORREIA, A. C. G. Propagação vegetativa de progênies de meios-irmãos de angico-vermelho (Anadenanthera macrocarpa (Benth) Brenan) por miniestaquia. Revista Árvore, Viçosa, MG, v. 36, n. 3, p. 389-399, 2012.

ELLSTRAND, N. C.; ELAM, D. R. Population genetic consequences of small population size: implications for plant conservation. Annual Review of Ecology and Systematics, Riverside, v. 24, p. 217-242, 1993.

FACHINELLO, J. C.; HOFFMANN, A.; NACHTIGAL, J. C.; KERSTEN, E. Propagação vegetativa por estaquia. In: FACHINELLO, J. C.; HOFFMANN, A.; NACHTIGAL, J. C. (Ed.). Propagação de plantas frutiferas. Brasília: Embrapa Informação Tecnológica, 2005. p. 69-109.

FERREIRA, B. G. A.; ZUFFELLATO-RIBAS, K. C.; WENDLING, I.; KOEHLER, H. S.; NOGUEIRA, A. C. Miniestaquia de Sapium glandulatum (Vell.) Pax com o uso de ácido indol butírico e ácido naftaleno acético. Ciência Florestal, Santa Maria, v. 20, n. 1, p. 19-31, 2010.

FERRIANI, A. P.; ZUFFELLATO-RIBAS, K. C.; HELM, C. V.; BOZA, A.; WENDLING, I.; KOEHLER, H. S. Produção de brotações e enraizamento de miniestacas de Piptocarpha angustifolia. Pesquisa Florestal Brasileira, Colombo, v. 31, n. 67, p. 257-264, 2011.

HACKETT, W. P. Donor plant maturationand adventitious root formation. In: DAVIES, T. D.; HAISSIG, B. E.; SANKHLA, N. Adventitious root formation in cuttings. Portland: Dioscorides Press, 1987. p. 11-28. (Advances in plant sciences series, 2).

HARTMANN, H. T.; KESTER, D. E.; DAVIES JUNIOR, F. T.; GENEVE, R. L. Hartmann and Kester's plant propagation: principles and practices. $8^{\text {th }}$ ed. São Paulo: Prentice Hall, 2011.915 p.
LATTUADA, D. S.; SPIER, M.; SOUZA, P. V. D. de. Pré-tratamento com água e doses de ácido indolbutírico para estaquia herbácea de pitangueiras. Ciência Rural, Santa Maria, v. 41, n. 12, p. 2073-2079, 2011.

LIMA, D. M. de; TANNO, G. N.; PURCINO, M.; BIASI, L. A.; ZUFFELLATO-RIBAS, K. C.; ZANETTE, F. Enraizamento de miniestacas de espinheira-santa (Maytenus ilicifolia Mart. ex Reissek) em diferentes substratos. Ciência e Agrotecnologia, Lavras, v. 33, n. 2, p. 617-623, 2009.

LIRAJÚNIOR, J.S. de;BEZERRA, J.E.F.; LEDERMAN, I. E.; SILVA JUNIOR, J. F. da. Pitangueira. Recife: Empresa Pernambucana de Pesquisa Agropecuária-IPA, 2007. $87 \mathrm{p}$.

LORENZI, H. Árvores brasileiras: Manual de identificação e cultivo de plantas arbóreas nativas do Brasil. 5. ed. Nova Odessa: Instituto Plantarum, 2008. v. $1,384 \mathrm{p}$.

. Plantas medicinais no Brasil nativas e exóticas. Nova Odessa: Instituto Plantarum, 2002. 512 p.

MARANGON, M. A.; BIASI, L. A. Estaquia de mirtilo nas estações do ano com ácido indolbutírico e aquecimento do substrato. Pesquisa Agropecuária Brasileira, Brasília, v. 48, n. 1, p. 25-32, 2013.

MARINHO, C. S.; MILHEM, L. M. A.; ALTOÉ, J. A.; BARROSO, D. G.; POMMER, C. V. Propagação da goiabeira por miniestaquia. Revista Brasileira de Fruticultura, Jaboticabal, v. 31, n. 2, p. 607-611, 2009.

OLIVEIRA, Y.; ALCANTARA, G. B.; GUEDES, I.; PINTO, F.; QUOIRIN, M.; BIASI, L. A. Substratos, concentrações de ácido indolbutírico e tipos de miniestacas no enraizamento de melaleuca (Melaleuca alternifólia Cheel). Revista Brasileira de Plantas Medicinais, Botocatu, v. 14, n. 4, p. 611-616, 2012.

RANGEL, M. S. A. Pitanga (Eugenia uniflora L). In: VIEIRA NETO, R. D. Frutíferas potenciais para os tabuleiros costeiros e baixadas litorâneas. Aracaju: Embrapa Tabuleiros Costeiros. Empresa de Desenvolvimento Agropecuário de Sergipe-Emdagro, 2002. p. 141-160.

SILVA, R. L. da; OLIVEIRA, M. L. de; MONTE, M. A.; XAVIER, A. Propagação clonal de guanandi (Calophyllum brasiliense) por miniestaquia. Agronomía Costarricense, San José, v. 34, n. 1, p. 99-104, 2010.

SILVA, S. de M. Pitanga. Revista Brasileira de Fruticultura, Jaboticabal, v. 28, n. 1, p. 1, 2006. 
SISTEMA METEOROLÓGICO DO PARANÁ SIMEPAR. O que você precisa. Solicitações dados meteorológicos. Curitiba: Centro Politécnico da UFPR, 2013. Disponível em: <http://www.simepar.br/site2/ faleconosco $>$. Acesso em: 29 out. 2013.

SOUSA, C. M.; BUSQUET, R. N.; VASCONCELLOS, M. A. da S.; MIRANDA, R. M. Effects of auxin and misting on the rooting of herbaceous and hardwood cuttings from the fig tree. Revista Ciência Agronômica, Fortaleza, v. 44, n. 2, p. 334-338, 2013.

SOUZA, J. C. A. V.; BARROSO, D. G.; CARNEIRO, J. G. A.; TEIXEIRA, S. L.; BALBINOT, E. Propagação vegetativa do cedro-australiano (Toona ciliata $\mathrm{M}$. Roemer) por miniestaquia. Revista Árvore, Viçosa, MG, v. 33, n. 2, p. 205-213, 2009.

TITON, M.; XAVIER, A.; REIS, G. G. dos; OTOLI, W. C. Eficiência das minicepas e microcepas na produção de propágulos de clones de Eucalyptus grandis. Revista Árvore, Viçosa, MG, v. 27, n. 5, p. 619-625, 2003.

VIEIRA NETO, R. D. Frutíferas potenciais para os tabuleiros costeiros e baixadas litorâneas. Aracaju: Embrapa Tabuleiros Costeiros / Empresa de Desenvolvimento Agropecuário de Sergipe-Emdagro, 2002. $216 \mathrm{p}$.
WENDLING, I.; FERRARI, M.; DUTRA, L. F. Produção de mudas de corticeira do mato (Erythrina falcata Bentham) por miniestaquia a partir de propágulos juvenis. Colombo: EMBRAPA Florestas, 2005. 5 p. (Comunicado técnico, 130).

WENDLING, I.; DUTRA, L.F.; GROSSI, F. Produção e sobrevivência de miniestacas e minicepas de ervamate cultivadas em sistema semi-hidropônico. Pesquisa Agropecuária Brasileira, Brasília, v. 42, n. 2, p. 289-292, 2007.

XAVIER, A.; SANTOS, G. A. dos; WENDLING, I.; OLIVEIRA, M. L. de Propagação vegetativa de cedrorosa por miniestaquia. Revista Árvore, Viçosa, MG, v. 27, n. 2, p. 139-143, $2003 \mathrm{a}$.

Enraizamento de miniestaca caulinar e foliar na propagação vegetativa de cedro-rosa (Cedrela fissilis Vell). Revista Árvore, Viçosa, MG, v. 27, n. 3, p. 351$356,2003 b$.

XAVIER, A.; WENDLING, I.; SILVA R. L. Silvicultura clonal: princípios e técnicas. Viçosa, MG: Ed. UFV, 2013. 279 p. 
